\title{
A STUDY OF LANGUAGE LEARNING STRATEGIES THAT SUCCESSFUL PRE-SERVICE TEACHERS UTILIZE IN ENGLISH PEDAGOGY PROGRAMS AT TWO UNIVERSITIES IN Concepción, ChILE: A CASE STUdy
}

\author{
Lea Hitt** \\ Mauricio Véliz ${ }^{* * *}$
}

\begin{abstract}
This study attempts to uncover the Language Learning Strategies (LLSs) utilized by proficient language learners in English pedagogy programs at two universities. It was found that students employ indirect strategies frequently, which are of a metacognitive nature. Through a case study methodology, these students were asked to do a semi-structured interview and a think-aloud protocol. It was found that cognitive and metacognitive strategies were the most prevalent.
\end{abstract}

Keywords: Language Learning Strategies (LLSs), metacognition.

\section{UN ESTUDIO DE ESTRATEGIAS DE APRENDIZAJE DE LENGUAS}

\section{ITULIZADAS POR ESTUDIANTES EXITOSOS DE PROGRAMAS DE PEDAGOGIA EN INGLÉS DE UNIVERSIDADES DE CONCEPCIÓN, CHILE: UN ESTUdio DE CASO}

\section{Resumen}

Este estudio procura develar las Estrategias de Aprendizaje de Lenguas (EALs) utilizadas por estudiantes avanzados en programa de Pedagogía en Inglés en dos universidades. Se estableció que los estudiantes de Pedagogía emplean estrategias indirectas con frecuencia, de naturaleza metacognitiva. A través de un estudio de caso, dos estudiantes fueron entrevistados y se les aplicó un procedimiento de pensamiento en voz alta. Se estableció que en ellos las estrategias cognitivas y metacognitivas son las predominantes.

Palabras clave: Estrategias de Aprendizaje de Lenguas, metacognición.

Recibido: 02-04- 2014

Aceptado: 24-12-2014

** Estadounidense, Magíster en Enseñanza de Inglés como Lengua Extranjera, Universidad Andrés Bello, Concepción, Chile. hitt.lea@gmail.com

*** Chileno, Doctor TESOL and Education, Exeter University, Universidad Andrés Bello, Santiago de Chile.mauricio.veliz@unab.cl 


\section{Introduction}

Learning success from elementary through secondary school level seems to be heavily contingent upon the quality of teachers; as the McKinsey Report (2007[1]) concludes of high- performing schools around the world, these systems consistently do three things well, "they get the right people to become teachers, they develop these people into effective instructors, they put in place systems and targeted support to ensure that every child is able to benefit from excellent instruction" (p. 13).

The term once used to describe successful students was "good language learner" by Rubin (1975), in which the first studies appeared because researchers wanted to know the 'characteristics' of students who successfully learned a second language. The strategies that were observed became known as Language Learning Strategies (LLSs) and continue to be studied and critiqued today; additionally, it is claimed that they can be taught.

Some of the early studies in LLSs date back to the seventies with the authors Stern and Rubin (1975), while later studies include authors such as, Nunan (1991), Oxford and Green (1995), and more recent authors include Dörnyei and Skehan (2003); the latter suggest the term self regulation to learner strategy. The earlier researchers investigated the so-called 'good language learners' and, "determined that such learners consistently used certain types of learning strategies, such as guessing meaning from the context" (Oxford, 2003, p. 10). The later studies showed that the less successful learners may have used the same strategies as more successful learners, but in an uncontrolled manner.

This study aims to uncover the strategies utilized by students who have reached proficiency in English during their university experience while having similar entry language levels as students who have performed poorly. The study will identify proficient students in the English pedagogy programs, identify the Language Learning Strategies they utilize, and finally, describe these strategies they utilize.

\section{Participants of the study}

The students of this study are from two universities in Concepción. The first university, and for the sake of this study is called University 1 , is a private university, located in downtown Concepción. University 2 is a traditional university and is located in the city of Concepción. 


\section{English pedagogy programs}

The English pedagogy program at University 1 consists of 114 students. The cohorts from 2009-2011 were chosen for this study because they are between their third and fifth years of the curriculum and therefore are not new, but have been learning English for at least a couple of years. The English pedagogy program at University 2 consists of 354 students. The cohorts from 2010 and 2011 were chosen for this study for the same reason as University 1.

\section{Literature review}

Introduction to Language Learning Strategies

Within the field of teaching English as a second language, much has been researched since the 1970s about learning strategies. Rubin (1975) explained in her well-known article regarding the 'good language learner':

It is common knowledge that everyone learns his first language with a fair degree of success, the reason being that everyone is born with the ability to learn a language and then grows up in a community in which he needs to function to some degree through language, the rules of which are imparted to him in the normal course of the day. Yet, it is equally common knowledge that some people are more successful (however this is defined) than others at learning a second language. (p. 54)

Thus, strategies began to be looked at as a way to understand what those good language learners were doing (the action they were taking) when they were successful at learning a second language. It is thought that less successful learners can use the correct application of strategies of the successful students, and what is more, that the strategies can be taught.

What exactly is a good language learner? Early authors described good language learners in regards to personal characteristics and strategies. A synthesis of the characteristics of good language learners discovered and mentioned in Zare (2012) is given here: they are learners who take responsibility for their learning and utilize metacognition by organizing and planning information about language; they are creative and experiment with grammar and words; they look for opportunities 
for practice in using the language; they utilize compensation strategies by continuing to talk or listen without understanding every word, and learn to make intelligent guesses.

At the beginning of research on Language Learning Strategies, late 1960s early 1970s, there was neither a theory to help guide researchers, nor empirical evidence into what strategies influenced learning a second language. Years later, language learning theory considered LLSs, which were initially linked solely to cognitive theory. Macaro (2001) explains cognition to be the way the brain holds, stores, retrieves, and processes information. Chamot and O'Malley (1990[2]) talk about both cognitive and metacognitive strategies, in which cognitive strategies are those almost subconscious things a learner does in a task, and the metacognitive include the planning, and organizing strategies, which support cognitive strategies. O'Malley and Chamot believe cognitive theory to encompass the idea that individuals 'process' information, and their thoughts involved in this cognitive activity are 'mental processes.' The authors state, "learning strategies are special ways of processing information that enhance comprehension, learning, or retention of the information" (p. 1).

Language Learning Strategies have been described by Rubin and Wenden in Zare (2012), as "any set of operations, steps, plans, routines, used by the learner to facilitate the obtaining, storage, retrieval, and use of information" (p.163). Another definition by O'Malley and Chamot in Zare suggests learning strategies as, "special thoughts or behaviors that individuals use to help them comprehend, learn, or retain new information" (p. 163). We can see that emphasis is placed on recall and retention of new information and processing that information to better comprehend it. Another definition cited frequently for LLSs states that they relate to "specific actions taken by the learner to make learning easier, faster, more enjoyable, more self-directed, more effective, and more transferable to new situations" (Oxford, 1990, p. 8). The study athand subscribes primarily to this definition. This emphasis is clearly demonstrating the learner as a self-directed learner, who is proactive and can control their learning.

Metacognition has been regarded as crucial in area of LLSs. According to Chamot (2004), "Strategic learners have metacognitive knowledge about their own thinking and learning approaches, a good understanding 
of what a task entails, and the ability to orchestrate the strategies that best meet both the task demands and their own learning strengths" (p. 14). A successful learner is one who thinks about what it takes to learn, and can match the appropriate strategy to the task. Another definition is given by O'Malley et al. in Zare (2012), which states that the metacognitive entails "strategies which involve planning for learning, thinking about the learning process as it is taking place, observing of one's production or comprehension, correcting your own mistakes, and evaluating learning after an activity is completed" (p. 164).

\section{Classification systems or taxonomies}

There are different ways to classify learning strategies; however, there is not one most accepted system. One of the most commonly used instruments (questionnaire) in determining the strategies used is the Strategy Inventory for Language Learning (SILL) developed by Oxford (1990). Oxford (1994) notes that about two dozen L2 strategy classification systems have been divided into these groups: 1) systems related to successful language learners (Rubin, 1975, p. 2) systems based on psychological functions (O'Malley \& Chamot, 1990); 3) linguistically based systems dealing with guessing, language monitoring, formal and functional practice (Bialystok, 1981) or with communication strategies like paraphrasing or borrowing (Tarone, 1983); 4) systems related to separate language skills (Cohen, 1990); and 5) systems based on different styles or types of learners (Sutter, 1989[3]).

Oxford's classification shows the strategies and the sets within them, and here is an explanation for each strategy as shown in Zare (2012). Direct strategies involve mental processing and are in three categories: memory, cognitive, and compensation. Memory strategies include mental processes for storing and retrieving new information. Cognitive entails the conscious ways of dealing with the target language. Compensation strategies enable learners to use the language despite knowledge gaps. Indirect strategies are metacognitive, affective, and social strategies, which provide indirect support for language learning. Metacognitive strategies allow learners to control their cognition by planning for a language task, organizing, setting goals, looking for practice opportunities. Affective strategies assist students in managing emotions and motivation. Social strategies facilitate learning through interaction with others. 


\section{Methodological framework}

Research methodology and methods

This study is considered to be qualitative survey-based research rather than quantitative because, even though there is a questionnaire that measures the frequency of strategies and a tabulation of results, qualitative inquiry may include quantification when it is part of a broader approach.

The particular instruments chosen were a questionnaire, a semistructured interview, and a think-aloud protocol. A questionnaire began the inquiry to aid in finding the most appropriate candidate, and was then followed by a semi-structured interview and a think-aloud protocol.

A questionnaire is not able to reach the complexities of individuals; therefore, diversity and context are often overlooked. For that reason, the SILL alone was not used, but rather two other instruments accompanied it. The questionnaire was applied to two groups of students, 13 from University 1 and 18 from University 2 in order to get a snapshot of Language Learning Strategy use of English pedagogy students.

Next, the semi-structured interview was chosen because it is a compromise between the two extremes of structured, where the format does not allow for spontaneity, and unstructured, which may stray from the topic.

Two pilot interviews were done before the actual interview. It was found that the pilot interview questions assumed the interviewee utilized certain strategies. The interview questions were changed to ask if they utilized strategies, for example, "How do you reduce anxiety?" was changed to "Have you experienced anxiety." If the answer was yes, the interviewer asks, "What do you do to try and reduce anxiety?" In addition, prompts for the interviewer were added in order to give examples in case the interviewee could not think of one.

Think- aloud protocols were the third instrument and they allow the researchers to observe what students do at the moment of performing a language task. Macaro (2001) describes think-aloud protocols as, "a process of articulating one's thoughts and actions as one is carrying them out" (p. 60). The subjects were given a language task of learning phrasal verbs and asked to articulate their thoughts while performing the task. 
An advantage of this method is that it provides insight into the decisionmaking process, and is a means of discovering when and in what way strategies are used.

\section{Sampling procedure}

Students for the interview were chosen according to the top two who utilize strategies with a high frequency as demonstrated by the SILL. The results indicated, and by coincidence, that there was one student at each university who was above the mean. For example, at University 1 , a student's average score was 4.1 (on a scale from 1-5) while the class mean for the SILL was 3.5. At University 2, a student's average score was 4.3 while the class mean was 3.4. It was found that they had succeeded in their work at the university as demonstrated by good grades in their courses, teacher comments as exhibited through class performance, and international exams passed with merit. Neither had lived in an Englishspeaking country nor had English-speaking parents or relatives. The student from University 1 was a fifth-year student and the student from University 2 was in her fourth year. Both students entered the university with a similar level of English.

\section{Research questions}

- Main research question (Following Oxford's classification of LLSs): Which Language Learning Strategies do successful English pedagogy students use?

- Secondary questions: What are the most prevalent LLSs that good learners use, direct or indirect?

- Do language learners exhibit a balance between frequency of use and use of strategy types?

\section{General objective}

Uncover the language learning strategies that students in English pedagogy at two universities in Concepcion, Chile utilize to successfully learn a foreign language.

\section{Specific objectives}

- Identify the Language Learning Strategies of successful students.

- Identify the most prevalent LLSs used, direct or indirect. 
- Determine the frequency of strategy use and use of strategy types.

\section{Results and discussion}

This study attempts to uncover the Language Learning Strategies that successful English pedagogy students at university utilize when learning a foreign language. It also aims to find out whether direct or indirect strategies are used more often, and if there is a balance between frequency of use and use of strategy types. The strategies are categorized according to Oxford's taxonomy (1990, p. 17).

\section{Language Learning Strategies utilized}

This section provides the results for the main research question: Which Language Learning Strategies do successful English pedagogy students use?

\section{SILL results}

The Strategy Inventory for Language Learning (SILL) was applied to two groups of students, 13 from University 1 and 18 from University 2 in order to get a snapshot of the Language Learning Strategy use of students. The average score at University 1 was 3.5, and the average at University 2 was 3.4. The standard deviation at University 1 was 0.3 while the standard deviation at University 2 was 0.5 , indicating a low standard deviation. Interestingly, there was one student at each university who scored above the average. The highest score was 4.1 at University 1 and 4.3 at University 2. The scores of the SILL show how often they use LLSs and the strategy types they use the most. The scores and what they indicate are shown below:

Figure 1. Score indicators

\begin{tabular}{l|l|l}
\multicolumn{1}{c|}{ Label } & \multicolumn{1}{c}{ Frequency } & \multicolumn{1}{c}{ Range } \\
\hline \multirow{2}{*}{ High: } & Always or almost always used & $4.5-5-0$ \\
\cline { 2 - 3 } & Usually Used & $3.5-4-4$ \\
\hline \multirow{2}{*}{ Medium: } & Sometimes Used & $2.5-3.4$ \\
\hline \multirow{2}{*}{ Low: } & Generally not used & $1.5-2.4$ \\
\cline { 2 - 3 } & Never or almost never used & $1.0-1.4$ \\
\hline
\end{tabular}


Despite the fact that this study did not intend to find a relationship between SILL results and student success, the results of the survey find that those students with the highest scores stand out academically.

Below are graphs, which illustrate the use of strategies of the sample from University 1, plus Student 1; it also presents the results from the sample from University 2, plus Student 2; finally, a comparison of both universities is presented, together with a comparison of Student 1 and Student 2 (Figures 5.1.2 and 5.1.3). The two groups of students do not vary significantly in their total score for strategy use (5.1.4). Both of the students who scored above the mean employ the metacognitive and social strategies the most. Student 1 received a score of 4.6 for metacognitive use and 4.8 for social strategy use. Student 2 received a score of 4.8 for metacognitive and 4.8 for social strategy use. It is interesting to take into account that the students have the same score, 4.8 , for the social type of strategy (Figure 5.1.5).

Figure 2. University 1 group and Student 1 average use of strategies (SILL results)

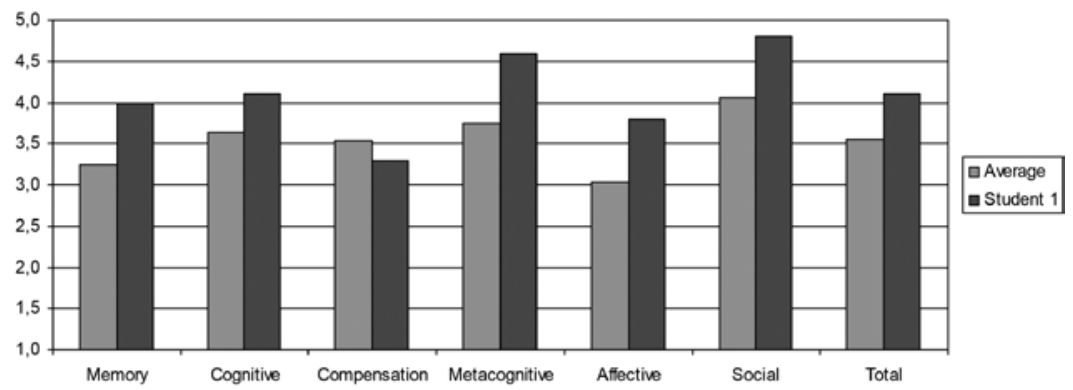

Figure 3. University 2 group and Student 2 average use of strategies (SILL results)

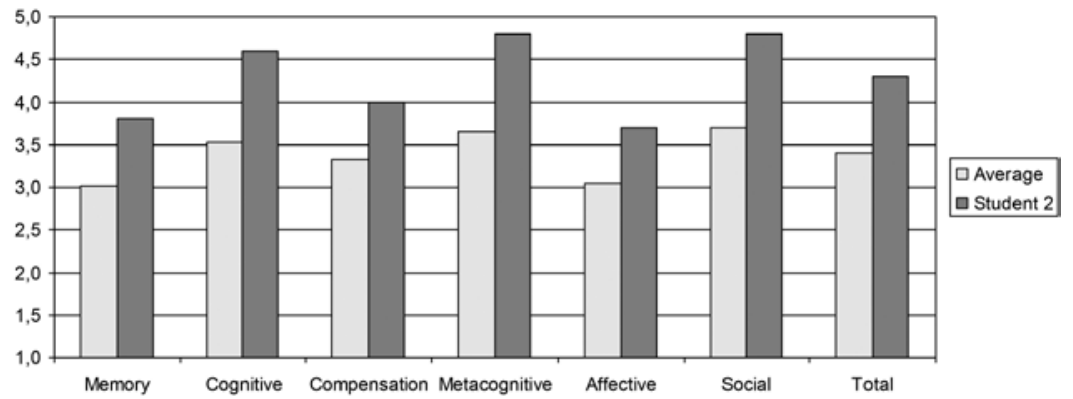


Figure 4. Comparison of University 1 and University 2 groups (SILL results)

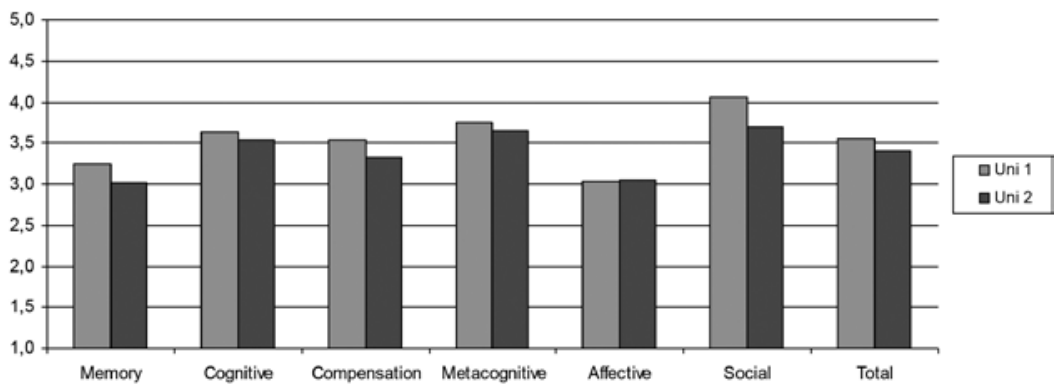

Figure 5. Student 1 and Student 2 comparison (SILL results)

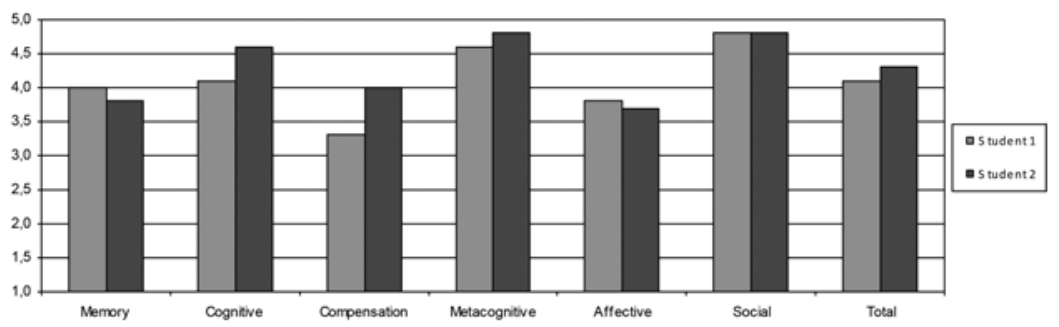

\section{Interview results}

The interview with Student 1 provided interesting insights into what she has been doing at university to learn a second language. The interview prompted responses to which strategies she uses, and both cognitive and metacognitive strategies stand out as the ones she mentions most frequently, while the other types, such as memory and affective, are referred to very infrequently or not at all. Cognitive strategies are those strategies that are utilized for understanding and producing the language. Oxford (1990) states, "Such strategies are a varied lot, ranging from repeating to analyzing expressions to summarizing. With all their variety, cognitive strategies are unified by a common function: manipulation or transformation of the target language by the learner". Student 1 mentions some of the cognitive strategies in her interview: watch movies (for example, \#15 of the SILL), write stories (\#17 of the SILL), watch shows on the Internet, practice perfect tenses, look at the definition of a word and use it every now and then. For example, she says, "I am really into watching shows on the Internet, I like the Graham 
Norton show, it is a British show, and it's really fun." She likes to learn English, as she mentioned in the introduction to the interview and it is evidenced here in that she utilizes strategies that make it more enjoyable for her to learn. The strategies of watching movies without subtitles, watching the British show, and looking for news in the target language are considered cognitive, specifically described in more detail by Oxford (ibid.), because she is practicing naturalistically, meaning practicing the new language in natural realistic settings, such as reading a book or article. Looking up a word in a dictionary may be classified as cognitive because she is looking for meaning of a word and breaks it down into parts (analyzing).

Metacognitive strategies are those that relate to how students manage their learning. Student 1 mentions that she listens to people talking to understand grammar, which is part of the metacognitive type because she is paying attention to specific aspects of language in use. She also plans to study before an exam and prepares for presentations by studying the topic, which is arranging and planning your learning, specifically planning for a language task. She evaluates her learning and pays attention to her mistakes and tries not to make them again, which is metacognitive as it entails self-monitoring, of which she is identifying mistakes when producing the language and trying to eliminate them. She knows how she learns, for example, she knows the topic of a speaking presentation she has to do and does not memorize it, but knows the topic well and uses her own words to explain it. She says, "I just study what I have to learn, but I don't study what I have to say to the public, my classmates write everything that they have to say. I speak with my own words, it's easier. If you forget a word, you forget the whole thing." Another metacognitive strategy that she mentions is that she speaks alone, in the mirror, to prepare for a presentation and when she has to read a text she does so alone, speaking out loud. These strategies are metacognitive because she is arranging and planning her learning. Metacognitive strategies, stated earlier by Rubin in Zare, "involve different procedures as planning, prioritizing, setting goals, and self-management," (p. 165). Student 1 is learning in an autonomous way, through the metacognitive strategies that have to do with organizing and creating the conditions for optimal learning.

Student 1 mentioned listening six times throughout the interview, which shows recognition on her part of her strength with this skill. 
However, listening is not a strategy, yet she may be very likely utilizing metacognitive strategies (overviewing and linking), for example. A strategic learner was defined in the literature review by Chamot as learners who have metacognitive knowledge about their own thinking and learning (2004, p. 14). Furthermore, memory, compensation, and social strategies were not mentioned as frequently, and no affective strategies were revealed. However, when asked directly about affective strategies use, she explains that knowing the topic keeps you calm, but she did not answer with an affective strategy that she uses, for example, making positive statements.

The interview with Student 2 provided interesting insights into what she has been doing at university. The interview revealed the use of memory, cognitive, and metacognitive strategies more than the other types. It is interesting to note that during the interview neither Student 1 nor Student 2 discussed the use of affective strategies, and social strategies were mentioned infrequently. Therefore, we have to wonder if these strategies are less important when learning a foreign language because these outstanding students do not mention them. A few memory strategies (those for remembering and retrieving new information) were mentioned such as, creating mental linkages by putting a new word into different contexts, using imagery by putting up paper on the walls of her room to see the words. She believes that she memorizes quickly, for example, she states, "I learn vocabulary very fast, sometimes when I have quizzes it takes me like thirty minutes to remember."

Cognitive strategies of Student 2, which include those strategies that are the conscious ways of dealing with the target language, are revealed in the interview when she mentions: watching movies without subtitles, reading blogs online, meeting with the native speaker language assistant, watching TV programs and cooking shows. These are strategies which are considered cognitive in that they are practicing the language naturalistically. This strategy shows that she is practicing the new language in naturalistic, realistic settings- watching a movie without subtitles and going to speak with the language assistant for example. When Student 2 talked about meeting with the native speaker language assistant at the university, this may be considered a social strategy because she is cooperating with others, specifically cooperating with proficient users of the language. At times, a strategy may 'overlap' because it can fit into more than one strategy type, as is the case here with 
meeting with a proficient user of the target language; therefore, it can be seen as both a cognitive and social strategy, and perhaps a third type. She also utilizes strategies of analyzing and reasoning when she reads and learns grammar rules because she is going from general to specific, a top-down strategy within the cognitive type. For example, she adds, "As I read, I learn new words and I also learn some grammar rules that I didn't know before." She also repeats words aloud and rehearses, which is practicing. Finally, she highlights and uses colors, which is creating structure for input and output, a cognitive strategy that helps one focus on important information.

Metacognitive strategies provide a way for learners to organize their learning process, and are mentioned by Student 2 when she seeks out practice opportunities. On three occasions throughout the interview she indicates that she looks for practice opportunities. In addition, she says she pays attention to her mistakes and tries not to make them again, which is self-monitoring. She makes time to study, and like Student 1, she also studies alone, which is organizing (one's schedule and physical environment for learning optimally).

Similarly to Student 1, Student 2 enjoys learning English and she knows how she learns. She began the interview by differentiating her skill level in speaking and writing, and said she feels more comfortable speaking. She states, "When I talk, in English, I mean I think that that's my big skill because it's easier for me to talk in English than, for example, writing, that's not my skill, but when I speak in English I feel more comfortable than writing." She enjoys learning English because she mentions things she loves to do such as, to watch cooking shows and to learn vocabulary related to cooking. She had fun in a debate as she describes here, "I was the last one to speak, I just exploded, I had fun, everybody said to me that I was anxious, not nervous, I like to speak in English."

Both Student 1 and Student 2 utilize cognitive and metacognitive strategies the most. They both utilize 'practice naturalistically' the most of the cognitive strategies, as they practice new language in natural, realistic settings, such as watching a movie without subtitles. They both underline words to focus their attention on an important word or phrase, and they both repeat and rehearse in order to practice. They are also interested in finding the meaning of new words through analyzing 
and reasoning. However, a difference is seen when Student 1 utilizes 'formally practicing with the writing system.' On the other hand, Student 2 has to write for classes at the university, but did not state a strategy related to it. Another difference is that Student 2 talked about memory strategies throughout the interview whereas Student 1 does not state any. Metacognitive strategies were similar in that they both create the space and time to learn English, self-monitor, and seek out practice opportunities. Student 1 employed a couple of more metacognitive strategies, which were "paying attention and planning" for a task. Social and compensation strategies were not stated frequently and affective strategies not once by Student 1 and once by Student 2 .

\section{Think-aloud protocol results}

The think-aloud protocol demonstrated that Student 1 employed cognitive strategies the most. She began by reading the first sentence aloud and then attempted to explain the meaning of a sentence with the phrasal verb 'keep from' by saying, "I think it's that she can't hide anything from her mum." Throughout the think-aloud protocol she employed this strategy of working out the meaning. This cognitive strategy is specifically, analyzing expression, as she is determining the meaning of a new expression by breaking it down into parts. At one point she employed a compensation strategy of guessing intelligently and using linguistic clues, as she thought the word 'confide' was similar to Spanish.

As she began to read the definitions of the phrasal verbs and match them to the sentences that contained the phrasal verb, she employed more of the same cognitive strategies of analyzing expressions because she used the meanings of various parts of the sentence to understand the phrasal verb, and utilized reasoning, too. After reading a definition of 'keep to myself' she says, "Right, because you don't tell anyone about your things so it's a secret, and you don't tell anyone about it." At then end of the think-aloud she says she would like to write down the words in her copybook to, "look at them in my house, more calm, and then I can incorporate this into my everyday English." This is a metacognitive strategy as she is organizing for learning language.

Student 2 employed cognitive strategies frequently throughout the think-aloud protocol. She began by reading the sentences to get a general 
idea and this corresponds to 'getting the idea quickly,' found within cognitive strategies. Other cognitive strategies included, 'highlighting' when she underlined words, and 'practicing' such as when she repeated the words. She said that, "I need to repeat it aloud because sometimes I just forget, so if I repeat it once more I can remember it more easily." She employed a couple of memory strategies, for example, when she recognized the word 'keep' as a word she knew from another kind of phrasal verb. This is a memory strategy, which is creating mental linkages; specifically she is relating new language to concepts already in her memory. She did this again when she wrote terms she already knew next to the definitions of the phrasal verbs she wanted to remember. At one point in the think-aloud protocol, she employed a metacognitive strategy by self-monitoring. She identified errors she had made in learning the definitions and so decided to start again.

Both students employed cognitive strategies the most for this task. The specific strategy they utilized was a bit different, though. Student 1 utilized analyzing expressions meanwhile Student 2 utilized repeating the sentences, words, and definitions. Student 2 underlined the words, which Student 1 did not do. They both utilized a metacognitive strategy, although different ones, Student 1 planned to study at home calmly while Student 2 self-monitored when she recognized errors in understanding the definitions. Student 1 utilized a compensation strategy (guessing intelligently) and Student 2 did not. Student 2 utilized a memory strategy (creating a mental linkage) and Student 1 did not. For this language task, neither of them employed the use of affective or social strategies.

To sum up, the SILL found that students at both universities have medium to high scores on their average use of strategies, and the scores do not differ greatly. However, a single student at each university scored above the average and was then investigated further through an interview and a think-aloud protocol. The SILL found that both students use metacognitive and social strategies the most. The interview uncovered that both students use cognitive and metacognitive strategies the most. Within cognitive strategies, they both utilize 'practice naturalistically' frequently, for example, speaking with native speakers, watching shows, and movies without subtitles. A difference discovered in the interview was the use of memory strategies by Student 2 and not by Student 1 . The think-aloud protocol found that they both used cognitive strategies the most to learn phrasal verbs. However, Student 1 analyzed the expressions 
and looked for meaning throughout the task while Student 2 repeated.

\section{Use of direct and indirect strategies}

This section provides the results of the research question: What are the most prevalent LLSs that successful learners use, direct or indirect?

\section{SILL results}

The SILL results from University 1 show that pedagogy students use almost the same amount of indirect strategies (3.6) as direct strategies (3.5). At University 2, students use slightly more indirect strategies, with a score of 3.5 while direct strategies are 3.3. Student 1 used more indirect strategies, with a score of 4.4, compared to direct strategies, which resulted in a score of 3.8. Student 2 used more indirect strategies with the same score of 4.4, while direct strategies resulted in a score of 4.1 . The similar and high score of both students in regards to indirect strategies is due to the fact that they both have the highest scores in the metacognitive and social strategy types, which are both part of the indirect category. The table below illustrates the differences in direct strategies (includes memory, cognitive, and compensation strategies) and indirect strategies (includes metacognitive, affective, and social strategies) of the SILL.

Figure 6. SILL results for direct and indirect strategies

\begin{tabular}{l|l|l}
\hline & \multicolumn{1}{|c|}{ Direct Strategies } & \multicolumn{1}{c}{ Indirect Strategies } \\
\hline University 1 & 3.5 & 3.6 \\
\hline University 2 & 3.3 & 3.5 \\
\hline Student 1 & 3.8 & 4.4 \\
\hline Student 2 & 4.1 & 4.4 \\
\hline
\end{tabular}

\section{Interview results}

The interview revealed that Student 1 uses more direct than indirect strategies by 1 point. She uses 8 direct strategies and 7 indirect strategies. Under direct strategies she uses 0 memory, 6 cognitive, and 2 compensation; for a total of 8 . Under indirect strategies she revealed the use of 5 metacognitive, 0 affective, and 2 social; for the total of 7 .

Student 2 indicated in the interview the use of more direct strategies than indirect strategies. She uses 10 direct strategies and 7 indirect 
strategies. Under direct strategies, she uses 4 memory, 5 cognitive, and 1 compensation; for the total of 10 . Under indirect strategies she revealed the use of 3 metacognitive, 1 affective, and 3 social; for the total of 7 . Both students indicated the use of slightly more direct than indirect strategies and this is in contrast to the SILL.

\section{Think-aloud protocol results}

Student 1 and 2 employed more cognitive strategies, which falls under the category of direct strategies. Direct strategies are those LLSs which "directly involve the target language," (Oxford, 1990, p.37). The task called for them to learn phrasal verbs in English. They employed all their mental processes to try and learn the phrasal verbs: they were analyzing expressions, understanding meaning, practicing and repeating, and underlining to focus on important information. In this task, they did not have the opportunity to do certain things, for example, to work with someone else and so they could not employ strategies such as social ones. This is similar to the interview results, but again, it is different than the SILL.

\section{Balance between frequency of use and use of strategy types}

The following section provides the results of the research question: Do successful language learners exhibit a balance between frequency of use and use of strategy types?

\section{SILL results}

The SILL total average tells how often the students use strategies for learning English, in other words, the frequency of use. Averages for each part of the SILL show which groups of strategies are used the most, as stated in research question 3- use of strategy types. Student 1 has a total score of 4.1 on the SILL. For score indicators, refer to Figure 5.1.1 in Section 1. The score of 4.1 is a high score and means that she uses LLSs 'usually.' The highest scores were metacognitive (4.6) and social (4.8). This means they are high, and she 'always or almost always' uses them. A low score exists for compensation, which she uses less (3.3), and this means it is 'sometimes used.' There is mostly a balance between frequency of use and use of strategy types for Student 1 as she has 'high' scores. Compensation is the strategy that is considered 'medium,' and lower from the rest. 
Student 2 has a total score of 4.3. This is a high score and means that she utilizes LLSs 'usually.' The highest scores of strategy types were cognitive, metacognitive, and social, and are 'always or almost always used' (high). As all the strategy types and the total average are in the same (high) category, there is a balance between frequency of use and use of strategy types. The table below shows the total scores and scores for each strategy type.

Figure 7. Total average scores and scores for each strategy type

\begin{tabular}{l|l|l}
\hline \multicolumn{1}{c|}{ Strategy Type } & \multicolumn{1}{c|}{ Student 1 } & \multicolumn{1}{c}{ Student 2 } \\
\hline Memory & 4.0 & 3.8 \\
\hline Cognitive & 4.1 & 4.6 \\
\hline Compensation & 3.3 & 4.0 \\
\hline Metacognitive & 4.6 & 4.8 \\
\hline Affective & 3.8 & 3.7 \\
\hline Social & 4.8 & 4.8 \\
\hline Total average & 4.1 & 4.3 \\
\hline
\end{tabular}

\section{Interview results}

The interview showed that there was an imbalance in the frequency of use and strategy type because Student 1 expressed the use of mainly cognitive and metacognitive types, and Student 2 revealed her use of memory and cognitive strategies more. The results of the interview indicate the high use of strategies, but not a balance among strategy types.

\section{Think-aloud protocol results}

The think-aloud protocol demonstrated that there was an imbalance in the frequency of use and strategy type because Student 1 and 2 primarily used cognitive strategies for this type of task.

Through the SILL, a balance between frequency of use and use of strategy types was exhibited. However, the interview and the thinkaloud protocol revealed an imbalance in that they employed several strategies within one or two strategy types. 


\section{Final remarks}

Language LearningStrategies are defined as the steps and actions taken by students to make learning easier and more enjoyable, and even more effective. We can see that Student 1 and Student 2 employed strategies that made learning easier, more effective, and more fun for them. First, the SILL showed a high use of metacognitive and social strategies, and that they were both above the average at their respective universities. Then, the interview allowed for rich detail of their experience studying the L2. The interview allowed for the uncovering of more detailed strategies (sub-categories). Both Student 1 and Student 2 revealed the use of cognitive and metacognitive strategies in the interview, and 'practicing naturalistically' within cognitive strategy types was brought to the surface such as, talking with native speakers and listening to TV programs and movies in English without subtitles. They both expressed employing this strategy frequently and said that they liked learning English. Student 1 and 2 evidence metacognitive, self-directed learning as they do what works for them and what makes learning more enjoyable. Thirdly, the think-aloud protocol allowed for a detailed look at strategies, in which they both employed cognitive strategies. The interview and the thinkaloud did not reveal the use of social strategies, as the SILL did, but this may be due to the type of questions asked and task given, or that there is less of a need for these strategies when learning a foreign language. This appears to relate to the literature on Language Learning Strategies that focus on cognitive and metacognitive strategies more so than other strategies. The authors, O'Malley and Chamot (1990) defined LLSs as, "special ways of processing information that enhance comprehension, learning, or retention of the information," (p. 1). This indicates the use of cognitive strategies, and the metacognitive would support those.

For research question 2, the SILL demonstrated that Student 1 and 2 use more indirect strategies. However, the interview showed that they employ slightly more direct strategies and the think-aloud protocol showed more direct strategies. The SILL provides a more global picture of strategy use while the interview and think-aloud allow for more details of what they do with specific language tasks. Once again, in question 3, the SILL indicates a balance between frequency of use and use of strategy types, but the other methods do not. The interview and the think-aloud showed an imbalance because the interview did not have 
enough questions specific to each strategy type and the think-aloud was a specific language task that led to the use of one strategy type.

Descriptive studies mentioned previously show similar results to this one in that successful learners demonstrate the use of metacognitive (support) strategies. For example, Macaro (2001) discusses the series of studies done in the 1990s, in which previewing the task, selective attention and scanning, planning and rehearsing linguistic elements, were used by the more successful language learners. As is seen in this study, the interview found that both outstanding learners used cognitive and metacognitive strategies. Both Student 1 and 2 employed the strategies that were most appropriate to the task. Green and Oxford in 1995, found more effective learners used strategies for active involvement in their learning. A more recent study by Anugkakul (2011) revealed that students with good and medium language proficiency employed all LLSs groups more frequently than students with poor language proficiency. This study demonstrated that both Student 1 and 2 employed more strategies than the other students, and they have taken an active role in their learning.

Yet another definition that fits Student 1 and 2, and that was seen before, is from Chamot (2004), "Strategic learners have metacognitive knowledge about their own thinking and learning approaches, a good understanding of what a task entails, and the ability to orchestrate the strategies that best meet both the task demands and their own learning strengths," (p. 14). The results discussed have revealed that the students know how they learn, know their strengths with the language, orchestrate various strategies, sometimes overlapping, and know how to best handle language tasks.

The implications of this study may indicate a need to teach strategies to pedagogy students so they can use them to develop skills and processes of the language, then becoming more proficient students who are prepared to teach English. Foreign language learning has not always been successful and not all researchers have even agreed upon the definition of Language Learning Strategies let alone if LLSs can and should be taught to learners. According to Macaro (2001), "However, our experience shows that foreign language learning is far from being universally successful even within the same classroom and with the same teacher" (p. 43). Therefore, to just teach the language is not enough; there is a need for students to become aware of how they can employ 
strategies appropriately. Macaro (ibid.) insists that, "learners will learn better if they are helped to identify the strategies they use," and "teachers need to know the strategies that their learners are using in order to better understand some of the problems they may be encountering" (p. 43).

It is necessary to investigate the less successful learners and what strategies they are utilizing, in what way or in what combination. Griffiths (2004) discusses a study that looked at under-achieving students and found that they were using similar strategies to those used by successful students. However, the difference seemed to be that the under-achieving students demonstrated less sophistication and a less appropriate response to a task. Furthermore, following the strategy use of a student from the beginning of a program to the end may also provide insight into the phenomenon and the success or failure of a student.

Student 1 and Student 2 used mostly cognitive and employ metacognitive strategies, which support the cognitive strategies. Therefore, it is of vital importance to use metacognitive strategies that support the direct strategies. It is less effective to use compensation, affective, and social strategies when learning a foreign language in an English pedagogy program, according to this study. Learners need to become consciously aware of how they learn, take an active approach to tasks, organize and preview a task, self-manage and self-monitor, in order to be more successful language learners. 


\section{References}

Anderson, N.J. (2005). L2 strategy research. Handbook of research in second language teaching and learning. 757-772.

Anugkakul, G. (2011). A comparative study in language learning strategies of Chinese and Thai students: a case study of Suan Sunandha Rajabhat University. European Journal of Social Sciences, 19 (2), 163-174.

Avalos, B. (2008). Critical perspectives on teacher education in neo-liberal times: Experiences from Ethiopia and Namibia. SARE, 14 (1-2), 9-27.

Barber, M. \& Mourshed, M. (2007). How the world's best-performing school systems come out on top. McKinsey \& Company.

Brandt, N. (2010). Chile: Climbing on Giants' Shoulders: Better Schools for all Chilean Children. Economics Department Working Papers, (784). Paris: OECD.

Chamot, A. (2004). Issues in language learning strategy research and teaching. Electronic Journal of Foreign Language Teaching, 1 (1), 14-26.

Chamot, A. \& O'Malley, J. (1990). Learning strategies in second language acquisition. Cambridge: Cambridge University Press.

Cohen, L. et. al. (2000). Research methods in Education. Great Britain: Routledge Falmer.

Cohen, A. \& Macaro, E. (2007). Language learner strategies: 30 years of research and practice. Oxford: Oxford University Press.

Dörnyei, Z. \& Skehan. P. (2003). Individual differences in second language learning. In Doughty, C.J., The handbook of second language acquisition. (pp. 589-630). Oxford: Blackwell Publishing Ltd.

Dörnyei, Z. (2005). The psychology of the language learner: individual differences in second language acquisition. Mahwah, NJ: Erlbaum. 
. (2007). Research methods in applied linguistics. Oxford: Oxford University Press.

Erhman, M. \& Oxford, R. (1995). Cognition Plus: correlates of language learning success. The Modern Language Journal, 79 (1), 67-89.

Ganschow, L. et al. (1998). Foreign language learning difficulties: an historical perspective. Journal of Learning Disabilities, 31 (3), 248-258.

Gao, X. (2004). A critical review of questionnaire use in learner strategy research. Prospect, 19 (4), 3-14.

- (2007). Has language learning strategy research come to an end? A response to Tseng et al. Applied Linguistics, 28 (4), 615-620.

Greenfell, M. \& Macaro, E. (2007). Claims and Critiques. In Cohen, A. \& Macaro, E. (Eds), Language Learner Strategies: 30 years of research and practice (pp. 9-45). United Kingdom: Oxford University Press.

Griffiths, Carol. (2004). Language learning strategies: theory and research. Occasional paper No. 1. Auckland: School of Foundations Studies.

Hsiao, T. \& Oxford, R. (2002). Comparing theories of language learning strategies: a confirmatory factor analysis. The Modern Language Journal, 86 (9), 368-383.

Lee, C. (2010). An overview of language learning strategies, ARECLS, 7, 132-152.

Macaro, E. (2001). Learning strategies in foreign and second language classrooms. China: Continuum International Publishing Group.

. (2006). Strategies for language learning and for language use: revising the theoretical framework. The Modern Language Journal, 90 (3), 320-337.

Oxford, R. (1990). Language learning strategies: what every teacher should know. NY: Newbury house. 
. (1994). Language learning strategies: an update. Eric Digest. Retrieved from www.eric.ed.gov. strategr.pdf.

. (1996). Employing a questionnaire to access the use of language learning strategies. Applied Language Learning, 7 (1\&2), 25-45.

. (2003). Language learning styles and strategies: an overview. Gala[5] Proceedings of GALA (Generative Approaches to Language Acquisition) Conference, 1-25. Retrieved from http: / / web.ntpu.edu.tw/ ?language/ workshop/ read2.pdf.

. (2011). Teaching and researching language learning strategies. Great Britain: Pearson Education Limited.

Richards, J. (2002). Methodology in language teaching: an anthology of current practice. United Kingdom: Cambridge University Press.

Richards, K. (2003). Qualitative inquiry in TESOL. Basingstoke: Palgrave Macmillan.

Rubin, J. (1975). What the good language learner can teach us. TESOL Quarterly, 9 (1), 41-51.

Tseng, W., et. al. (2006). A new approach to assessing strategic learning: the case of self-regulation in vocabulary acquisition. Applied Linguistics, 27 (1), 78-102.

Véliz, M. (2011). Language learning strategies (LLSs) and L2 motivations associated with L2 pronunciation development in pre-service teachers of English. Literatura $y$ Lingüistíca, 25, 193-220.

Westwood, Peter. (2008). What teachers need to know about teaching methods. Australia: Acer Press.

Zare, P. (2012). Language learning strategies among EFL/ESL learners: a review of literature. International Journal of Humanities and Social Science, 2 (5), 162-169. 